\title{
Making Prints: How Learning Printmaking During Pandemic Can Boost Students' Creativity
}

\author{
Agnisa Maulani Wisesa ${ }^{1, *}$ Wida Rahayuningtyas ${ }^{2}$, Iriaji $^{1}$, Ike Ratnawati $^{1}$ \\ ${ }^{1}$ Art Education Program, Art and Design Department, Faculty of Letters, Universitas Negeri Malang, Indonesia \\ ${ }^{2}$ Music and Dance Education Program, Art and Design Department, Faculty of Letters, Universitas Negeri Malang, \\ Indonesia \\ *Corresponding author. Email: agnisa.fs@um.ac.id
}

\begin{abstract}
Initially, this research was based in the idea of combining online and offline classroom materials to teach art (Blended Learning). But since the start of 2020, learning everywhere have been pushed towards non-physical because of pandemic. Challenges in teaching art practices becomes visible and emphasised. Although Blended Learning method had been implemented in Art and Design Department of Faculty of Letters in Universitas Negeri Malang learning and teaching practices, it is proven that online based works better as supplement rather than main learning platform. Studio time in printmaking course becomes less relevant in this crisis, thus making prints at home with available and homely tools can make students relate printmaking principles to real life situation. The methodology of this research is experimentation, observation finished by qualitative study of the students' progress. Although challenges may appear enlarged, the result until now is quite comprehensive that students are exploring more tools and material in order to understand basic printmaking principles. On side note, because the students are using easy obtainable materials, the process also reduces more chemical residue and appear more friendly for future greener art curriculum.
\end{abstract}

\section{Keywords: Printmaking, Blended Learning, Print Studio, Pandemic, Art Education}

\section{INTRODUCTION}

Earlier this year has been a shockwave to all fields, not only just in education, but also everything else. A pandemic that started to spread in late 2019 has bring the era of disruption into test. Technology has either helped us or challenge us into individuals that needs to adapt more to fast-paced information exchange. Education happened to have prepared a long way before with technology-based approach, such as blended learning [1] and flippedclassroom [2].

Ideally, blended learning approach is practiced in a 50-50 classroom environment [3] as well as flipped classroom [4]. The idea is to give students learning time inside their comfortable space and then combine it with classroom environment. This approach is ideal to support the fastpaced information that is accessible for the students everywhere. With that, we should also agree that learning nowadays needs to aim for individual goals and students' engagement to learning [5]. To motivate and attach them to their own process. Thus, blended learning and flipped classroom approach needs to facilitate that.

In this ongoing research since the start of this year, our first goal was to provide individual learning platforms and times, so students can adjust their learning pace to the ongoing curriculum. Blessing in disguise or not, the start of pandemic accelerates this research into test. Can an online learning platform give accurate learning guidelines to students throughout their learning process? Is it possible for every student to achieve the main goal of the practicebased course that they are partaking? And how can virtual learning platform be a proponent factor to a studentcentered practice-based art course?

\section{CASE STUDY: PRINTMAKING COURSE}

Universitas Negeri Malang has an Art and Design department that provides numerous practice-based courses. Because the university's goal is to bring in qualified art teachers for upcoming society [6]. One of those courses happened to be printmaking.

Printmaking itself is a collective-minded practice [7]. Many of its art were and are produce within a studio setting that needs strict regulations and order. Thus, basically in a printmaking course, students are not just taught to print an artwork, but also understands about system, learn to get accustomed to printing order, and most importantly committed to their work. Without a physical studio, all these goals sounded impossible at first, yet very challenging to be done.

So, we tried to incorporate the blended learning approach and flipped classroom settings to deliver learning materials of printmaking course, so the students can practice 
distance learning of the course. There is still no apparent result whether this approach will deliver students with high printmaking proficiency or skillful in specific printing technique. Yet, until now, these students happened to show tremendous progress in understanding printmaking. From three main goals of the printmaking course, all of them are achieved by adjusting to their surrounding resources and exploring possibilities from observing things around them. The methodology will be explained in the following section.

The printmaking course's participants are about 94 students aged 19-21, divided in three classrooms. We use Google Classroom platform to incorporate flipped classroom approach in delivering learning materials as well as giving students time to report their personal progress. Following that, Zoom and Google Meet are used as virtual meeting room, or as we would like to call it virtual studio.

\section{METHODOLOGY}

Of course, the first step that we did was to prepare all the learning materials via online platform. In flipped classroom and blended learning approach, educators needs to provide accessible learning materials that students can explore, such as shared slides, modules, videos and reading materials. By this step we have done it via Google Classroom. We divided 94 students into three huge virtual classrooms, with each class approximately have 30-33 students. The students can see learning materials that scheduled to be visible in specific times following the semester's timeline. This is the part where the students can independently explore their learning materials in specific timeline. Please refer to the image below to see scheduled learning materials.

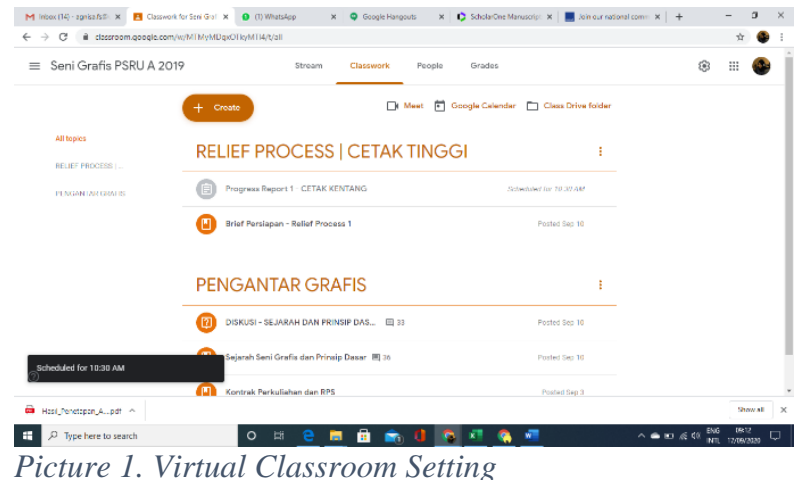

Secondly, the students are given period to not only explore the learning materials but also to consult over it. So, in that period, educators have scheduled a virtual meeting that the students are able to ask and consult directly to educators. In addition to Q\&As in every virtual meetings, educators also live-streamed the process themselves to motivate students do the same thing. Meetings can be seen in pictures attached below.

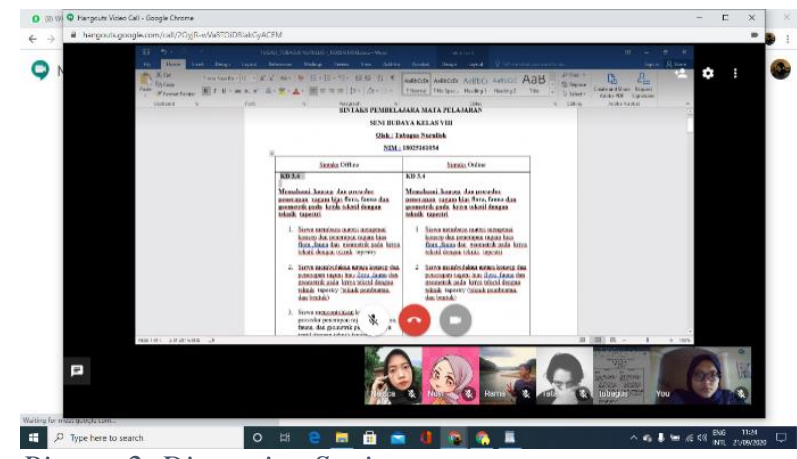

Picture 2. Discussion Setting

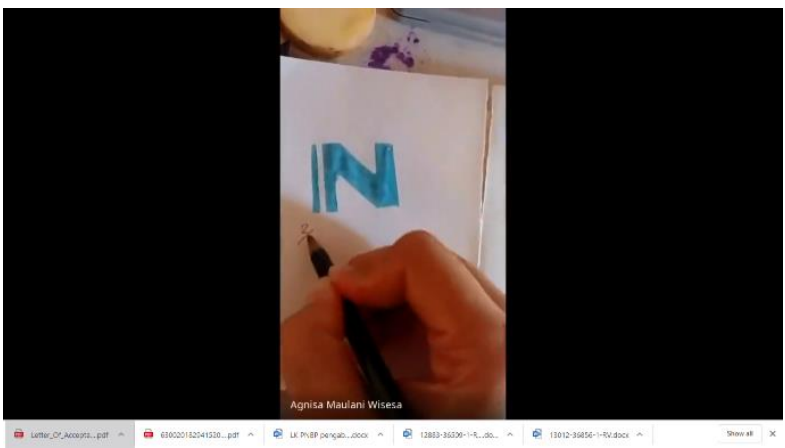

Picture 3. Tutorial Setting

After students given the time to consult and perform their understanding, they are required to submit two different progress, which are, their creation process from making the matrix [8], their printing process and their working space. Their final artwork is also a mandatory to submit after three to four weeks process in .jpg or .pdf file format. They are required to portfolio their printing process and photograph each one of the prints as well as the whole edition in lined up. Pictures are shown below.

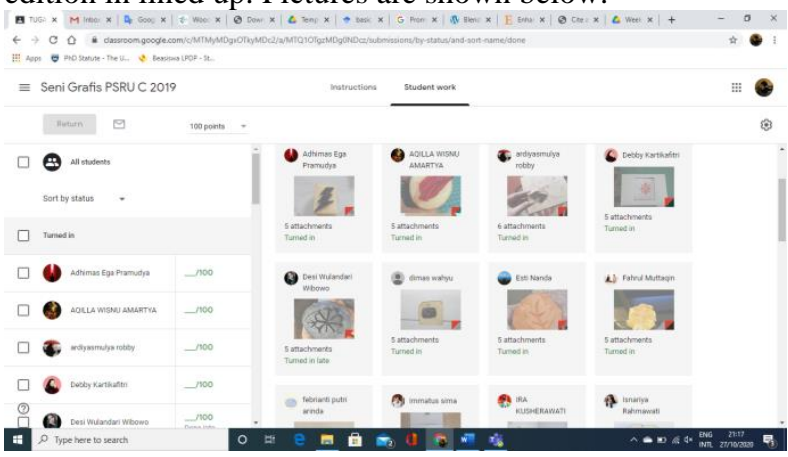

Picture 4. Assignments

Students are given feedbacks about their works in one to two weeks given the lecturers time to analyse their process. Basically, the factors that are being observed are their time of process, their methodology, their commitment in finishing an artwork as well as their final artwork. All of those are done virtually via online platforms to avoid physical contact. 
There are several interesting findings that happens during the observation time as well as the learning process. Analysis will be explained in the following section.

\section{FINDINGS AND DISCUSSION}

This research started in early February before the pandemic news widespread in Indonesia. So the plan before was to make a 50-50 classroom environment with virtual settings. But the condition begged to differ during late March. Learning resources was prepared during February to March, so basically there was a swift change of course that needed to be done to adjust to new learning habit. The hardest part in preparing online and virtual materials were in the period planning, type of evaluation as well as assessment. Because practice-based course like printmaking are usually supervised during studio time, either by lecturers or by studio advisors. Thus, the learning materials also needed to be adapted to become flexible, either in material or in tools. Goal is still the same, the students understand the basic printmaking technique [8], planographic, intaglio, relief, and screen print.

There are four video tutorials in Indonesian that is created to be learning resources based on each printmaking technique. Every technique is given four weeks to explore, because every course has only 16 weeks in the department. Up until now there are two printmaking techniques that has been taught. Relief and Screen-Print. Relief process is taught with basic woodcut with water-based ink that is inspired by ukiyo-e [9] printing technique from Japan. Here is the result of the exploration.

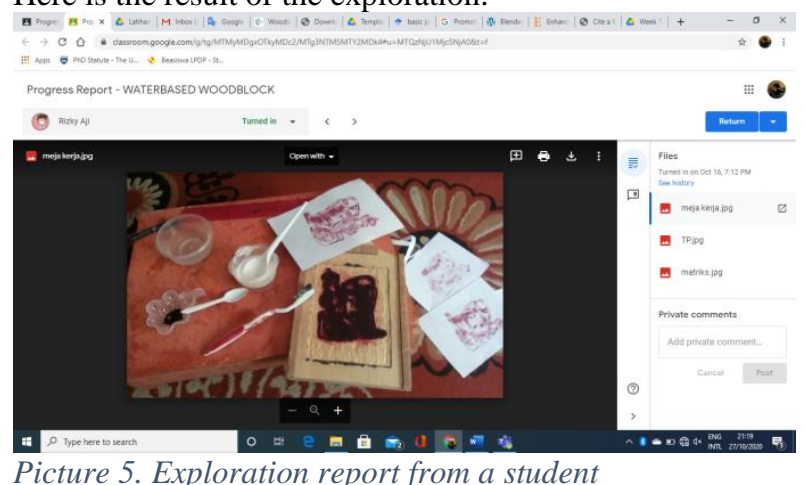

Students are given time to explore how to make the waterbased ink with the similar approach with ukiyo-e. Although they are not really producing ukiyo-e, they are exploring the water-based material freely. This gives them space to be creative as well as innovative in using any kinds of found materials and innovating with standard tools that they can found at home.

Most students feel it is harder for them to concentrate at home when they are trying to print, yet they are more motivated to use any kinds of ingredients at home to achieve ideal art print. For example, in this water-based technique of printmaking, the students are required to make water-based ink with glue-like solidity that is used to gum the pigment/ink to the paper. These students use boiled water and corn starch, some used rice flour and any plant-based starch. Their glue-like liquid exploration with different ingredients was pretty much succeeded. Picture is shown below.

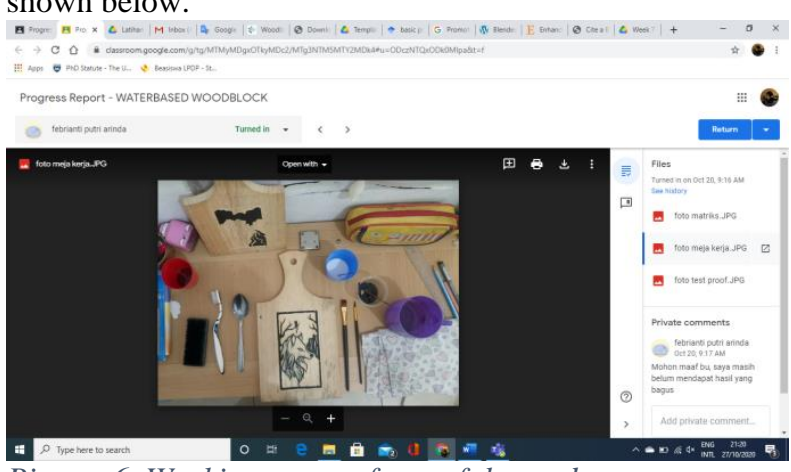

Picture 6. Working space of one of the student

Their printing exploration were also pretty much of a success because they tried to use different kind of tools to substitute baren [10] in printing the woodblock. They use from spoon, bottles as well as rice ladle. Picture is shown below.

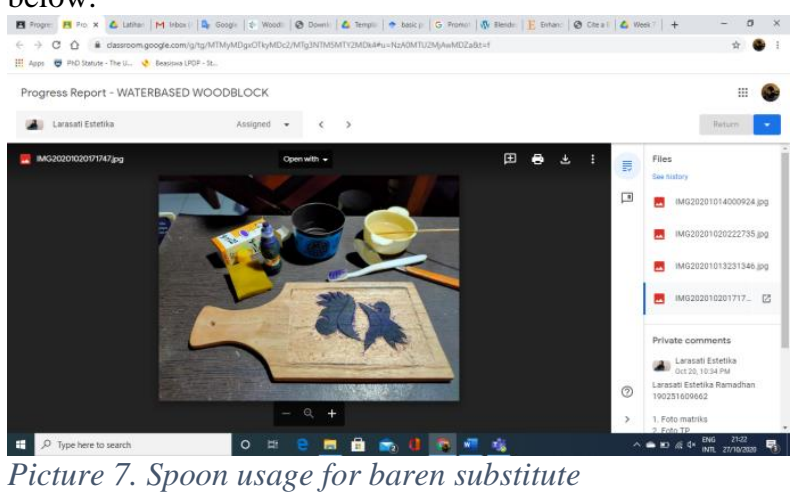

As mentioned before, this exploration is still ongoing, but up until now this exploration method in trying to find substitutes for printing ingredients and materials are going good, and the students are also more active in responding to instructions as well as more open to alternative materials as well as media. This is from an eight weeks observation.

But this exploration does not just have excellence, but also have some drawbacks. Those drawbacks are including some inaccuracy in delivering the goals of the whole experiment then some students are missing the whole point to finish their process rather than caught up in exploring ingredients. That is why periodical supervision is also important in this process.

\section{CONCLUSION}

From the findings and explanation above, we conclude that this remote learning about printmaking can be an alternative for students to explore more simple and easyto-get materials in making art prints. Those exploration helped students a lot with their creativity process and give them thorough understanding as well about the origin of some printing materials. Such as pigments, inks, matrixes, and so on. But of course, the setbacks are also things to be 
considered too. Because some students are too caught up in those exploration process and they tend to stray far from what they are supposed to do which are finishing a project. So, this method definitely needs a lot of improvement.

To make virtual studio is as resourceful as physical studio needs a lot of trial and error as well as a lot of experiments in multi-disciplinary fields. That is why as researcher in this settings, we hope that this research would not only give more examples about doing a practice-based course in virtual setting, but also means to trigger other practicebased course approaches to make collective platform in order to facilitate future learning experiences. This pandemic is not just making a huge disruption to the world, but somehow also accelerates technology to be more human-centered.

\section{REFERENCES}

[1] Nortvig, A. M. (2020). Digital expansions of physical learning spaces in practice-based subjects-blended learning in Art and Craft \& Design in teacher education. Computers \& Education, 104020.

[2] [4] Keengwe, J. (. (2014). Promoting active learning through the flipped classroom model. IGI Global.

[3] Valiathan, P. (2002, October 1). Blended learning models. Learning circuits. Retrieved from www.purnimavaliathan.com: https://www.purnima-valiathan.com/wpcontent/uploads/2015/09/Blended-Learning-Models-2002ASTD.pdf

[5] Gilboy, M. B. (2015). Enhancing student engagement using the flipped classroom. Journal of nutrition education and behavior, 109-114.

[6] Visi, Misi, Tujuan | Universitas Negeri Malang (UM). (2020). Retrieved 10 October 2020, from https://um.ac.id/tentang-um/visi-misi-tujuan/

[7] Bodman, S. L. (2012). Against the grain: Knust print collective. Printmaking Today, 21(2).

[8] Griffiths, A. (1996). Prints and printmaking: an introduction to the history and techniques. Univ of California Press.

[9] Bell, D. (2004). Ukiyo-e Explained. Global Oriental.

[10] Tools and Materials / Adachi's Authentic Ukiyoe | Adachi Woodcut Prints UKIYOE Online Store. (2020). Retrieved 27 October 2020, from https://www.adachihanga.com/ukiyo-e-

en/quality/tools/index_en.html\#: :text=The $\% 20$ baren $\% 20 \mathrm{r}$ ubbing\%20pad\%20is,wrapper\%20made $\% 20$ from $\% 20$ bam boo $\% 20$ skins. 